\title{
BRID HENDRON: 'PEOPLE TALK ABOUT MANAGING STRESS WHEN WHAT WE NEED TO BE DOING IS ELIMINATING IT'
}

Brid Hendron is a GDP and has a special interest in relaxing nervous, anxious and phobic patients. She holds an NLP trainer qualification and is also qualified in hypnosis. Brid provides training for healthcare professionals in advanced communication skills.

\section{What or who inspired you to be a dentist?}

I'm a farmer's daughter and my mother was a general nurse. When I was growing up in Armagh, our kitchen was the local triage centre, so at any time you could walk in to find somebody having a fracture assessed or their blood pressure taken. I just loved watching my mother manage that and people were so grateful. That is what inspired me to go into something healthcare related but the dentistry bit was infinitely less inspired.

I actually started in medicine, rather than dentistry, at Trinity in Dublin. In those days medicine and dentistry were mixed for the first two years. Within about two months I had figured out that the dentists were a more relaxed bunch and probably going to be a lot more fun to spend five and half years with. So I convinced both the dean and myself that I would be better suited to dentistry. I have never regretted it and I really enjoy my chosen career. I'm very practical and in dentistry there is great satisfaction in being able to see a treatment through from start to finish. Mammy is still triaging in the kitchen and now I pitch in when I go back home.

You are not just a GDP but you also practise coaching and have qualified in hypnosis and acupuncture - what drove you to study these topics?

After I qualified, I ended up in single-handed practice in Letterkenny, a large rural market town in the Republic of Ireland. This was the
'I was lacking the skills to help my patients to have a more comfortable experience of dentistry...' early 1990s and people didn't have a lot of money. There wasn't much health education and dentistry would not have been a priority. The very nature of all of that meant that many people were attending my surgery purely because they were in pain or something was broken. Invariably that meant they arrived with an empty stomach having had trouble eating or without having had much sleep. They usually had to squeeze it into the market day too, so they were also under time pressure. That meant that there was a whole cohort of patients I was caring for that had had a less than favourable experience of dentistry in the past. I was acutely aware of that. As a result I got very good diagnostically and with my hands, but I was lacking the skills to help them to have a more comfortable experience or at least a better perception of dentistry. I really hadn't a clue where to start to fix this but I figured that maybe I needed to be a bit more considerate, so I did a counselling course. But that didn't suit me at all because you can't really give advice when you're counselling. I'm very direct and solution-focused by nature so I thought I'll have to look at something else. Life coaching was coming into vogue then and I thought it sounded quite interesting. I did a distance learning course and that was great. It was the first time I really appreciated that people could

\section{CLEVER COMMUNICATION \\ The same piece of information can take very little communicating or significantly more depending on the recipient and the tools available \\ - It's not dissimilar to an occlusal restoration in this regard - frequently you won't know until you start how long, ultimately, it will take \\ The trick is to accept this: celebrate the quick wins and tolerate the occasions when you might have to drill deeper.}

change their mind or, maybe more significantly, that you could help people to do so. I could see that was the problem with my cohort of patients: they needed to change the way they interpreted dentistry. I stumbled across the British Society of Medical and Dental Hypnosis (which is now the British Society of Clinical and Academic Hypnosis) and went over to London for a weekend course which introduced me to a whole fraternity of people who were trying to achieve exactly the same thing as me. They were trying to assist people to have a better experience of medicine or dentistry. That encouraged me greatly and led me to explore other tools such as neuro-linguistic programming (NLP) and straight coaching.

At that time these techniques were more commonplace in the business arena than in healthcare so a lot of my apprenticeship was served in the business field. Even today I still do a bit of business coaching. Eventually I sold the practice in Letterkenny and came over to London to follow that through where I spent many years working with individual dentists, their teams and their patients accompanying them through all sorts of changes and challenges. I am now back in Armagh.

\section{Did you go through coaching yourself?}

Yes, as part of the training you must go through the process yourself. Personal experience made me aware of its actual power. It never ceases to amaze me how much potential we have in our minds. Some elements of coaching come back to basic principles - talking things through and getting perspective from others. 
In the past, a lot of what is 'coaching' happened in extended family units around the kitchen table. You came home, talked a problem through and got lots of different perspectives. Now that the world is such a transient place and communities are changing all the time we are losing that. That's why coaches, acting as an independent person with your best interest at heart, have become more mainstream. I don't think that the wisdom is new, just the packaging.

\section{Why neuro-linguistic programming (NLP)?}

I found NLP to be a particularly useful model for teaching because it was a simple way of explaining very complex concepts. Dentists don't have time to do a psychology degree; however, we absolutely need to understand people, so an easy-to-follow model is very useful. Within dentistry NLP is used to improve our communication. We all have a common intention to do the right thing for each patient. NLP provides tools that help us to take care of ourselves, manage our stress levels and to have an easier day every day leaving us better placed to deliver care more effectively.

\section{How can dentists learn to control their reactions to stressful situations?}

It really frustrates me that people continue to talk about managing stress when really what we need to be doing is eliminating stress. We want to keep ourselves healthy and working optimally for longer. Northern Ireland dentistry has recently lost some very good people to suicide. We need to sort this out.

To me stress is being in a negative state; whether that is being angry, annoyed, or frustrated, those emotions stress your system. There is wisdom in the language we have used for years: 'snap out of it', 'you need to shake it off' or 'you need to move on' That's exactly what you need to do, you need to shake it off between patients and move on. If we are to be emotional at work, it's going to be very draining. The aim isn't to manage your anger or disappointment; it's not to get there in the first place. Easier said than done but once you feel the benefits it gets easier.

Part of this is understanding what your triggers are. For example, understanding why a certain type of patient presses those buzzers or why a dynamic in the team is problematic, which you repeatedly tolerate though it drives you mad. Then you can work out what you need to do in order to address that in a way that is effective for everybody. If you are concealing negative feelings all day every day, it does have a cumulative impact. Low level, chronic exposure is much more damaging than one-off high impact stress. We should not teach people to just accept their work as difficult. Our graduates should be encouraged to adapt, learn or change what they need in order to have, on the whole, a positive experience at work.

\section{There is some speculation around the evidence base behind NLP. In what ways have you found it to be effective?}

Initially, NLP was based on replicating excellence. Although now it has reached areas, such as sales, where it could be used with less than a pure intention, in its actual inception they took the top three communicators in the US at that time and broke down the elements that made them excellent. It's modelled on people who are naturally brilliant at what they do. I think it's important to remember that. Some parts of it I don't use, have never used and never taught. But there is a lot there that is very useful. I don't really know any other way of teaching these skills as fluidly and clearly.

Managing your state is really important. There is an element of NLP that says that if you are in a negative state you can't have optimal behaviour. Now, it's in everyone's interest, yours and your patients', to get the best result every time. There is no feeling sweeter than going home after a day of things going really well. If techniques and skills like NLP can help us to achieve that outcome, to me it doesn't matter what the evidence base is as long as it assists us to do a better job for our patients. I know many of the things that I teach do really help people in their professional life to do a better job. I don't argue with people who are sceptical. It might not be everyone's cup of tea and I wouldn't want it to be. But I think that people who run with NLP to see what it can do shouldn't be criticised for doing so.

Issues around communication are always cited as one of the main reasons behind patient grievances escalating to official complaints what would help dentists avoid this problem?

It's interesting because it's one of those things that we are not particularly well prepared for. Not every brilliant clinician is going to be a brilliant communicator and not every brilliant communicator is going to be a brilliant clinician. The difference is that we wouldn't let a poor clinician out of dental school without giving them assistance to get them up to speed yet frequently if our communication skills aren't particularly good we aren't necessarily given the support that we need. It is assumed that we will learn on the job.

I think what we need to do now is step up to the challenge. This is already happening: communication skills are now pretty much part of the undergraduate curriculum across the board and are featuring more and more on postgraduate calendars. Practices are actually bringing in communication coaches like myself with experience in healthcare and voluntarily upskilling. It just takes time for that to have an impact. All day every day you will be communicating, whether it is with the team or with the patients. However, the most important communication of all is how you communicate with yourself in your head. Good communication starts there. Understanding how your own mind works and how that may be different or similar to others is the critical bit for me. That's the part that massively reduces the stress.

\section{Talking about oral sex habits with patients in order to identify risk factors for HPV is becoming very important for dentists. What communication approaches do you recommend to tackle this topic?}

We have to remember that all we are doing is transferring information, we are not passing judgement. We have been here before. I am old enough to remember when we were told that we were going to have to start saying to parents that they might be feeding their children the wrong things. Everybody thought this was going to be an absolute nightmare and that parents were never going to accept this from a dentist. Interestingly, out of the 44 people I lectured to this morning, not one of them considered smoking cessation to be difficult anymore. We will rise to this new challenge and we will begin to transfer the information about oral sex and HPV to our patients, the same way we have done for smoking and sugar intake.

I hope that we have learned from previous instances and we do this quickly because I really think we can make a change here. Oral cancer is a significant and horrific disease. The more we demonstrate ourselves rising to these challenges and making a difference as a profession, the more we demonstrate our worth within healthcare. The more we do that, the louder our voice and the louder our voice, the more we are listened to when recognition and budgets are being divvied out.

of all the parties involved in healthcare, I honestly believe that we dentists are the most flexible communicators. We do more communicating than the average healthcare 
practitioner in a shorter window, often discussing diagnosis, results, treatment plans, options, risks, benefits, procedures, postoperative instruction and money all in the one visit.

\section{How do you approach the care of nervous patients and those with phobias?}

When I am working with people the most important tools are the simplest things - curiosity, how this is a problem for them for instance, and enthusiasm, because usually by the time they get to me everybody is tired of listening to their problem, even themselves. More often than not the last thing a nervous patient wants to do is to set the problem aside, which we sometimes feel as clinicians is the best approach - to make light of it as it were. Patients want to explore it and talk about it. Sometimes they just want someone to be sympathetic and compassionate about it and I am blessed with the privilege of time to listen. There is so much support for nervous patients now where there wasn't in the past. It's fantastic that people with dental phobias can now go for CBT, sedation or see someone like me. I love the fact that people contact me to find out how they can actually help their anxious patients.

\section{What type of patient do you find to be the most challenging?}

The patients I still sometimes find most challenging are the small number who do not exhibit a lot of information either in facial expression or verbally. These patients used to panic me because I am very expressive myself. I would have assumed these patients didn't like me or that I wasn't getting through to them, where really their agenda was: 'it's just the dentist, let's do what we need to do!' I used to find that really confusing. Curiously that type of patient often likes a lot of detail, so when they do ask something they want specific, accurate information. I personally have very big picture style of thinking and being drawn down into the detail is a challenge for me. I've improved because I know it's important, but I used to resist that. I thought that people were checking up on what I knew. That type of thing is really useful for dentists to know - these
'I don't think

that the

wisdom in

coaching is

new, just the packaging...' patients are not checking up on you, they just need to understand details of the treatment and know they are okay with it.

\section{What is your typical week like - how do you fit it all in?}

It is very different every week. Next week for example I am in London on Monday because I have two business coaching clients that I see face-to-face occasionally. On Tuesday I will be working with the Health and Social Care Board in Northern Ireland. I have an advisory role there, which is a two-year post around the implementation of some pilots. I've stepped out of my clinical role while I'm in this post but I still do one clinical session a month in Dublin with phobic patients. On Wednesday I am delivering a team communication training in a dental practice. On Thursday I will be working in another advisory role, this time with the Northern Ireland Medical and Dental Training Agency around planning and implementing the postgraduate calendar. It's one of the best jobs in the world because it means I am always abreast as to what is going on and I've made some fantastic friends with the people I've met. On Friday I have two patients in the morning for one-toone coaching for dental phobia in a non-clinical environment. So every week is different; busy but very varied. I love it.

\section{Can you explain how acupuncture can be used to treat patients with problematic gag reflexes?}

Nobody really knows how it works, though there are lots of theories. Specifically for the gagging there is one acupressure point in the centre of the chin that undoubtedly has the capacity to suppress the gag reflex. Now how much of it is placebo and how much of it is real is an ongoing debate. I do know that for a lot of people it significantly decreases their likelihood to gag. Also it's really helpful to be able to say to a patient you have something else to try because it demonstrates that you genuinely would like this to be an easier experience for them. That in itself - attention and care - is often enough for them to be able to relax and not panic about gagging.

\section{What are you most proud of in your career to date?}

I'm proud of every single patient who has overcome a phobia. I know many of the journal's readers will have had that experience of helping someone who found dentistry really difficult and that same patient now has a very relaxed experience of their dentistry. It's enough to bring tears to your eyes. It's empowering for us as professionals, and for the patient as a person because if you have a true fear of something and you overcome it you feel like you can do anything. People do often go on to do really amazing things afterwards. It's nice to be witness to that.

\section{Top tips to help practices} become more patient friendly?

The word 'friendly' is really important here. To me friendly practices are like friendly people.

- You expect a warm welcome from a friendly practice just as you would from a friendly person

- You expect a friend to know you are coming and be pleased to see you

- You also expect them to be generous with their time. Sometimes you might not need much and other times you might need more

- You also expect to be remembered, valued and appreciated.

A comfortable practice is a different thing. I have been in the plushest practices that have been so incredibly comfortable but not at all friendly and I have also been in the friendliest practices that were not exactly designed for comfort. I know which I prefer.

\section{What do you do in spare time?}

I have a six-year-old son so my spare time involves ferrying him to things as is the case for most mothers!

We also have a lovely place by the sea, back where I first started out in dentistry in Donegal, and I like nothing more than to go walking there.

Also, I love stories - I love hearing stories, going to the theatre and listening to singer-songwriters. My husband is very into music so I spend a lot of time with him listening to folk music and story-telling. That's a shared interest between the two of us. INTERVIEW BY RUTH DOHERTY 